\title{
Practical Aspects of OEE in Automotive Company - Case Study
}

\author{
Małgorzata Jasiulewicz-Kaczmarek \\ Faculty of Engineering Management, \\ Poznan University of Technology, \\ Poznan, Poland \\ E-mail: malgorzata.jasiulewicz- \\ kaczmarek@put.poznan.pl
}

\begin{abstract}
Measure is initial and basic step in taking actions striving for excellence in an organization. To maintain competitive advantage in the market, enterprises use various tools enabling measuring efficiency. In the paper the most often cited in literature and implemented in practice measure of efficiency of manufacturing equipment utilization called Overall Equipment Effectiveness is presented.
\end{abstract}

Keywords- Overall Equipment Effectiveness (OEE); availability;automotive industry

\section{INTRODUCTION}

The commonly applied standard and to some extent principle in the context of management is the often cited and paraphrased sentence by Peter Drucker "when an organization can measure its own performance then it can be managed". Measure increases curiosity and discussion on measurement results provide understanding of processes, their capacity [1], allows to focus on important characteristics, problems [2] and builds reliability [3, 4, 5]. Campbell and Jardine [6] gave the commonly-classified maintenance performance indicators as measures of:

- equipment performance, such as its availability, reliability and overall equipment effectiveness (OEE),

- process performance, such as the ratio of planned to unplanned work or scheduled compliance,

- cost performance, such as the costs for labor, material and maintenance.

The goal of the hereby paper is to analyze the Overall Equipment Effectiveness in the automotive industry company. The paper is composed of five chapters and starting with introduction. The second chapter includes analysis of the literature on the subject of measuring efficiency of production equipment use. The next chapter provides presentation of the company and OEE measurement methodology. The subject of the next chapter is analysis of results of the research conducted and discussion on positive and negative aspects of customize model of OEE measurement. The fifth chapter is the summary of the work and conclusion.

\section{LITERATURA REVIEW}

One important metric to ascertain the productivity of individual equipment, called overall equipment effectiveness (OEE) was devised by [7] under the Total Productive

\author{
Mariusz Piechowski \\ Implementation and Development Department, \\ IQ - software, \\ Poznan, Poland \\ E-mail: mariusz.piechowski@iq-software.pl
}

Maintenance (TPM) umbrella. The author defines the losses which reduce the effectiveness of the equipment, classifies it into six major categories (TABLE I) and proves that OEE measurement is an effective way of analyzing the efficiency of a single machine in the manufacturing system.

TABLE I. ClaSSIFICATION OF LOSSES ACCORDING [7]

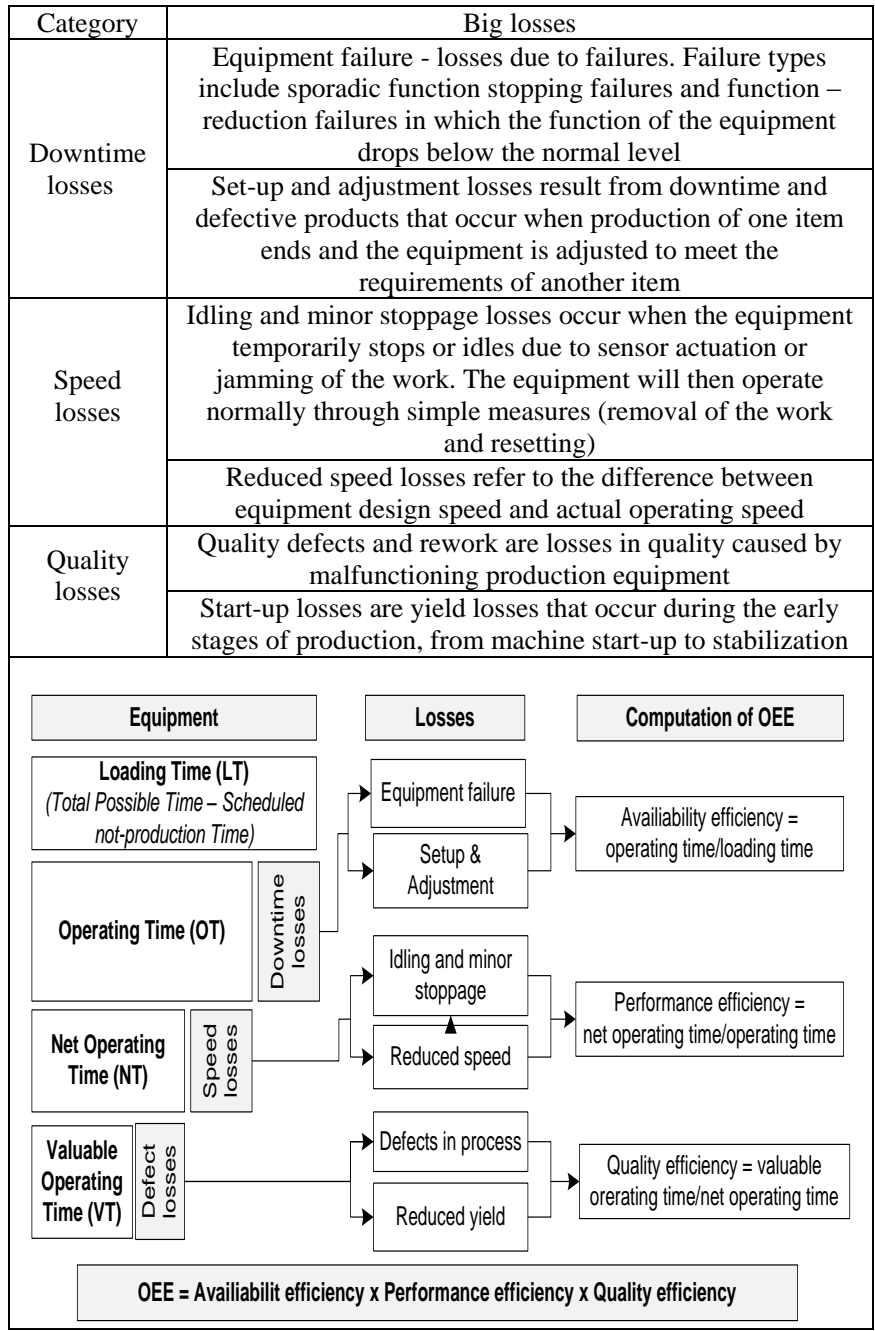

OEE, by identifying and quantifying losses, enabled professionals to address their problems and measurably improve performance, making it a popular metric. Analytically, OEE can be expressed as the ratio between what was actually manufactured and what could be ideally 
manufactured or, alternatively, as the fraction of time in which an equipment works at its full operating capacity. The concept of OEE is variously used in industry with modifications to suit the particular industry and the objective of measurement. Dal et al. [8] suggest that OEE can be used for example as a benchmark on many various levels of manufacturing environment: enterprises as a whole, production line or isolated machine and referred to future values of OEE and define levels of improvements to be made. The analysis of the literature proves that generally differences in the definition of OEE are mostly the result of:

- The approach to losses definition ([7], [9], [10]),

- The intended implementation area, e.g. single machine, production line, entire company ([11], [12], [13], [14], [15], [16], [17], [18], [19], [20]),

- Specific characteristics of an industry ([21], [22], [23], [24], [25]).

Although OEE originated as a part of TPM, it has also been used extensively outside the maintenance paradigm [19]. The Scopus search delivers 114 documents (20.07.2016). The figure 1 shows a short Scopus analysis. The pie chart shows the document allocation by subject areas and the line chart displays the trend of the documents by time which includes the keyword "overall equipment effectiveness (OEE)".
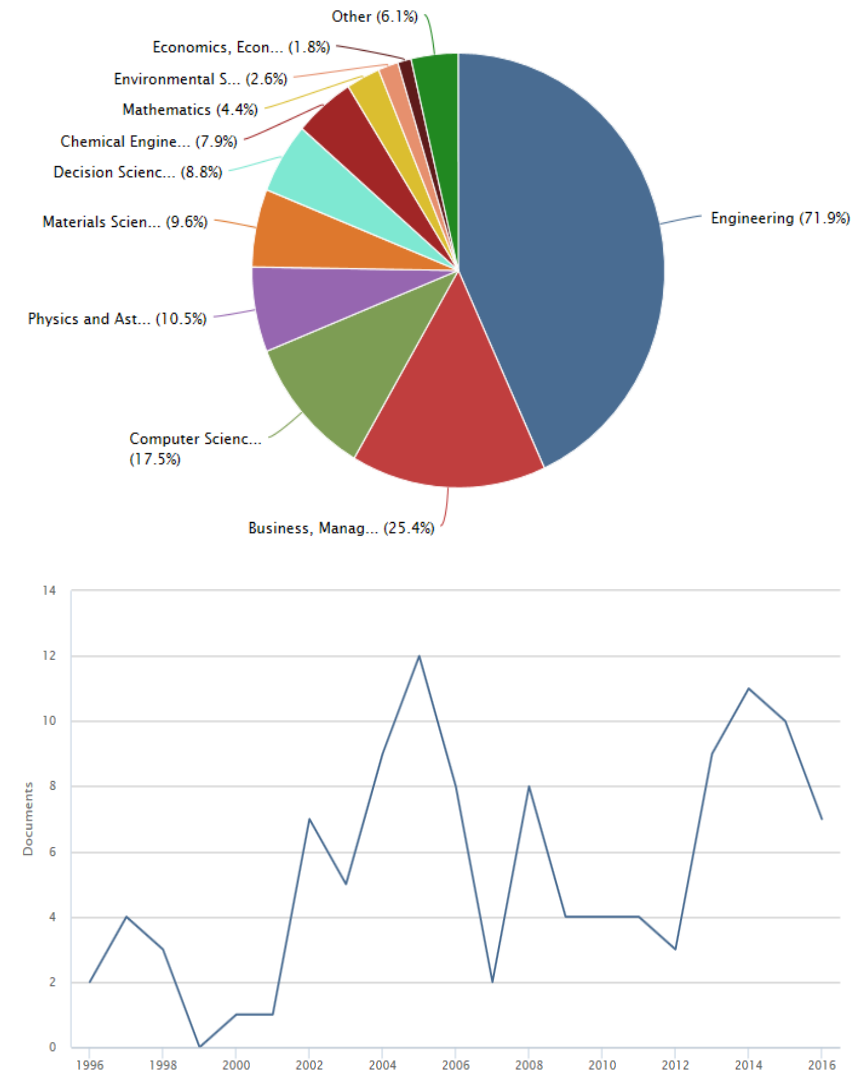

Figure 1. Documents by subject areas and time.

The database does not index all published documents. However, even that reference proves that the OEE is the measure popular both among academic researchers and business practitioners.

\section{CHARACTERISTICS OF RESEARCH OBJECT AND MODEL OF OEE ASSESSMENT}

\section{Company Presentation}

The company, which is the subject of the study, is a leader in the production of die casting of aluminum alloy, precision machining of aluminum and iron castings for the automotive industry. The company specializes in the production of parts for turbochargers and brake systems. For several years, the company has been benefiting from the concept of Lean Manufacturing, which in its scope covers all departments of production as well as the non-productive departments. Within the system, tools such as 5S, SMED, Kaizen Events are implemented, and from nearly a year the company has been implementing the concept of Total Productive Maintenance. The result of applying Lean concepts are the standards of implementation of production processes (procedures and instructions for the operators) and performance measuring system for the production area developed in the enterprise.

Making the decision to improve maintenance area in accordance with the concept of TPM was another project by the management towards building competitive advantage. One of the steps taken for the implementation of the concept was development of OEE measurement model.

Previous actions implemented in the framework of Lean and data on the machine (data on MTBF and MTTR indicators) and their role in the process enabled assessing the criticality of machines and nominating the group of machines for which the OEE measure is to be carried out first. Classification of machines and devices due to their influence on safety, quality and continuity of production process was carried out with the help of a decision tree and a matrix developed by the technical department of the company. Machinery and equipment were allocated to three groups A, $\mathrm{B}$ and $\mathrm{C}$. The company identified 32 strategic machines (CNC machines and casting machines), which are classified as the group A (for them OEE assessment is to be conducted in the first place), 72 machines have been qualified as the group B, the other machines and devices 112 as the group C.

\section{OEE model}

The following section provides the formulae for each element of the OEE calculation in the company. The first of these elements is machine availability. The availability element of the OEE measure is concerned with the total stoppage time resulting from unscheduled downtime, process set-up and changeovers, and other unplanned stoppages. In simple terms, it is the ratio of actual operating time to the planned operating time (Eq. 1). 


$$
\text { Availability }=\frac{\text { Operating time }}{\text { Planned operating time }}=\frac{O_{t}}{P_{t}}
$$

Planned operating time is calculated by subtracting from the Theoretical production time the scheduled break for employees (TFO - $15 \mathrm{~min}$ ), the setup time (TPZ - $20 \mathrm{~min}$ ) and the additional break for employees ( $\mathrm{Tp}$ - $15 \mathrm{~min}$ ) resulting from the fact that the company employ people with disabilities. Operating time $\left(\mathrm{O}_{\mathrm{t}}\right)$ is obtained by subtracting downtime from planned operating time. Loss of time is analyzed in four categories (TABLE II): losses related to machine (PR), losses related to tool (TT), non-productive intervals (PP) and new releases (NBR)

TABLE II. CATEGERIES OF LOSSES FOR “AVAILABILITY RATE”

\begin{tabular}{|c|c|c|}
\hline Source & Losses & Description \\
\hline \multirow{4}{*}{ PR } & 1.1 & Planned maintenance (operator is involved) \\
\cline { 2 - 4 } & $\mathbf{1 . 2}$ & Short downtime - problem eliminated by the operator \\
\cline { 2 - 4 } & $\mathbf{1 . 3}$ & Large failure \\
\hline \multirow{4}{*}{ TT } & $\mathbf{2 . 1}$ & Tool failure (mold failure, emergency mold cleaning) \\
\cline { 2 - 4 } & $\mathbf{2 . 2}$ & Changeover \\
\cline { 2 - 4 } & $\mathbf{2 . 3}$ & Tool servicing (planned cleaning, seals replacement) \\
\cline { 2 - 4 } & $\mathbf{2 . 4}$ & Setups - mold exchange or processing (casting \\
department)
\end{tabular}

Data is manually collected in the computer system. The formula for calculating "Availability rate" implemented in the company is presented in the TABLE III

TABLE III. “AVAILABILITY” OF A CNC MACHINE FOR 3 SHIFTS

\begin{tabular}{|c|c|c|c|c|c|c|c|c|c|c|c|c|c|c|c|c|c|c|}
\hline \multirow{3}{*}{ v } & \multirow{2}{*}{\multicolumn{4}{|c|}{$\begin{array}{c}P_{t}[\mathrm{~min}] \\
\text { planned production } \\
\text { time }\end{array}$}} & \multirow{3}{*}{$\mathrm{P}_{\mathrm{t}}$} & \multicolumn{11}{|c|}{ Downtime [mim] } & \multirow{3}{*}{$\begin{array}{c}\mathrm{O}_{\mathrm{t}} \\
\min \end{array}$} & \multirow[b]{3}{*}{$\%$} \\
\hline & & & & & & \multicolumn{3}{|c|}{ PR } & \multicolumn{3}{|c|}{ TT } & \multirow{2}{*}{\multicolumn{2}{|c|}{\begin{tabular}{|c|}
$\mathrm{NBR}$ \\
$\bar{m}$
\end{tabular}}} & \multicolumn{3}{|c|}{ PP } & & \\
\hline & $\mathrm{T}_{\mathrm{d}}$ & $\mathrm{T}_{\mathrm{p}}$ & $\mathrm{T}_{\mathrm{pz}}$ & $\mathrm{T}_{\mathrm{fO}}$ & & $\therefore$ & 2 & 2 & $\bar{i}$ & तู & (3) & & & $\bar{F}$ & $\underset{7}{\mathrm{z}}$ & 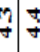 & & \\
\hline I & 480 & & 20 & 15 & 445 & & & & & & & & & 10 & & & 435 & 0,98 \\
\hline II & 480 & & 20 & 15 & 445 & & & & & 27 & & & & & & & 418 & 0,94 \\
\hline III & 240 & & 20 & 15 & 205 & & & & & & & & & 22 & & & 183 & 0,89 \\
\hline
\end{tabular}

The second element of the OEE calculation is " $\mathrm{P}$ performance rate". The indicator is calculated according to the formula presented below (Eq. 2):

$$
\text { Performance }=\frac{\text { Net operating time }}{\text { Operating time }}=\frac{o_{\text {nt }}}{o_{t}}
$$

Net operating time is calculated as the ratio of the number of goods produced on the machine by theoretical time of the operation performed $(\mathrm{Ct})$. $\mathrm{Ct}$ parameter is usually associated with how fast a machine runs. In practice, it is necessary to define the $\mathrm{Ct}$ parameter taking into consideration actual conditions the machine is to work in and parameters of products that are to be processed. Hence, calculation of performance requires definition of $\mathrm{Ct}$ standards for every product. The formula for calculating "Performance" indicator implemented in the company is presented in the TABLE IV.

\begin{tabular}{|c|c|c|c|c|c|c|c|c|c|c|c|}
\hline \multirow[t]{2}{*}{ 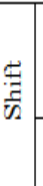 } & \multicolumn{4}{|c|}{$\begin{array}{c}\mathrm{P}_{\mathrm{t}}[\mathrm{min}] \\
\text { planned production } \\
\text { time }\end{array}$} & \multirow[t]{2}{*}{$P_{t}$} & \multirow[t]{2}{*}{$0_{t}$} & \multicolumn{2}{|c|}{$\begin{array}{c}\text { Output } \\
\text { [pcs] }\end{array}$} & \multirow{2}{*}{$\begin{array}{c}\mathrm{C}_{\mathrm{t}} \\
\mathrm{pcs} / \mathrm{min}\end{array}$} & \multirow{2}{*}{$\begin{array}{c}0_{n t} \\
\min \end{array}$} & \multirow{2}{*}{$\begin{array}{l}\mathrm{P} \\
\%\end{array}$} \\
\hline & $\mathrm{T}_{\mathrm{d}}$ & $\mathrm{T}_{\mathrm{p}}$ & $\mathrm{T}_{\mathrm{pz}}$ & $\mathrm{T}_{\mathrm{fo}_{0}}$ & & & $\mathrm{O}_{\mathrm{pt}}$ & $R_{p t}$ & & & \\
\hline I & 480 & & 20 & 15 & 445 & 435 & $4 / 4$ & 29 & 1,15 & 412,2 & 95 \\
\hline II & 480 & & 20 & 15 & 445 & 418 & 456 & 7 & 1,15 & 396,5 & 95 \\
\hline III & 240 & & 20 & 15 & 205 & 183 & 64 & 23 & 1,15 & 55,65 & 30 \\
\hline
\end{tabular}

TABLE IV. "PERFORMANCE" OF A CNC MACHINE FOR 3 SHIFTE

The third and final element of the OEE calculation is the "Q - quality rate". Quality is calculated by subtracting the output during running time by rejects (including reworks) and then dividing by the output (Eq. 3). The number of products that do not meet quality specification is calculated by the operator after completing each shift.

$$
\text { Quality }=\frac{\text { Actwal output }- \text { Recects }}{\text { Actwal output }}=\frac{o_{p t}-R_{p t}}{o_{p t}}
$$

For the moment, the plant has a data collection and analysis tool named QMS (OEE basis), designed by the consulting firm. It is developed in SQL Server 2014: the data collection remains in the form of manual entry while the analysis of different losses is an automated process.

\section{USING THE TEMPLATE}

The period of the first month after development of OEE model and its components is validation of the model. The data entered to the system on each shift and each day was

\begin{tabular}{|c|c|c|c|c|c|c|c|c|c|c|c|c|c|c|c|}
\hline \multirow{4}{*}{$\frac{5}{n=1}$} & \multicolumn{6}{|c|}{ OEE zmianowe } & \multicolumn{9}{|c|}{ OEE dzienne } \\
\hline & \multirow{3}{*}{$\min$} & $\mathrm{O}_{\mathrm{t}}$ & A & $\mathrm{P}$ & \multirow{3}{*}{$\begin{array}{l}\mathrm{Q} \\
\%\end{array}$} & \multirow{3}{*}{$\begin{array}{c}\text { OEE } \\
\%\end{array}$} & \multirow{3}{*}{$\begin{array}{c}\mathrm{P}_{\mathrm{t}} \\
\text { min }\end{array}$} & \multirow{3}{*}{$\frac{\mathrm{O}_{\mathrm{t}}}{\min }$} & \multicolumn{2}{|c|}{ Output } & \multirow{3}{*}{\begin{tabular}{|c|}
$\mathrm{O}_{\mathrm{tt}}$ \\
$\min$
\end{tabular}} & \multirow{3}{*}{\begin{tabular}{l|}
$\mathbf{A}$ \\
$\%$
\end{tabular}} & \multirow{3}{*}{\begin{tabular}{l|l}
$\mathbf{P}$ & \\
$\%$ &
\end{tabular}} & \multirow{3}{*}{$\begin{array}{l}\mathrm{Q} \\
\%\end{array}$} & \multirow{3}{*}{$\begin{array}{c}\text { OEE } \\
\%\end{array}$} \\
\hline & & & & & & & & & $\mathrm{O}_{\mathrm{pt}}$ & $R_{p t}$ & & & & & \\
\hline & & $\min$ & $\%$ & $\%$ & & & & & pcs & pcs & & & & & \\
\hline I & 445 & 435 & 98 & 95 & 93,88 & 87 & & & & & & & & & \\
\hline II & 445 & 418 & 94 & 95 & 98,46 & 88 & 1095 & 1036 & 935 & 994 & 864 & 95 & 83 & 94 & 74 \\
\hline III & 205 & 183 & 89 & 30 & 64,06 & 17 & & & & & & & & & \\
\hline
\end{tabular}
observed (TABLE V).

TABLE V. OEE OF A CNC MACHINE FOR ONE DAY

Most of the problems in this period was primarily the result of the erroneous data input into the system and the 
regularity of data recording. Analysis of the data and the information obtained during meetings with production and maintenance department staff led to developing a training plan. Trainings were focused mostly on creating the habit of entering data into the system and on proper allocation of data (assigning events to the appropriate category of losses). The result of the trainings was development of standards for data entering into the system by operators and maintenance staff.

After half a year period after training sessions, another comprehensive analysis of OEE and its components for all strategic machines (casting machines and $\mathrm{CNC}$ ) was conducted. Its aim was to answer the following questions: Is the equipment effective? If poor performance exists, where does it come from? What are the principal losses? Which actions should be taken to solve the problems and to improve the performance? The sample graphs presenting OEE and its components (A- availability, P - Performance, Q - quality) for all the casting machines (KPZ), for a selected casting machine (STO1094) are shown in Figure 2 and MTTR indicators for the casting machine STO1094 are shown in the Figure 3 .

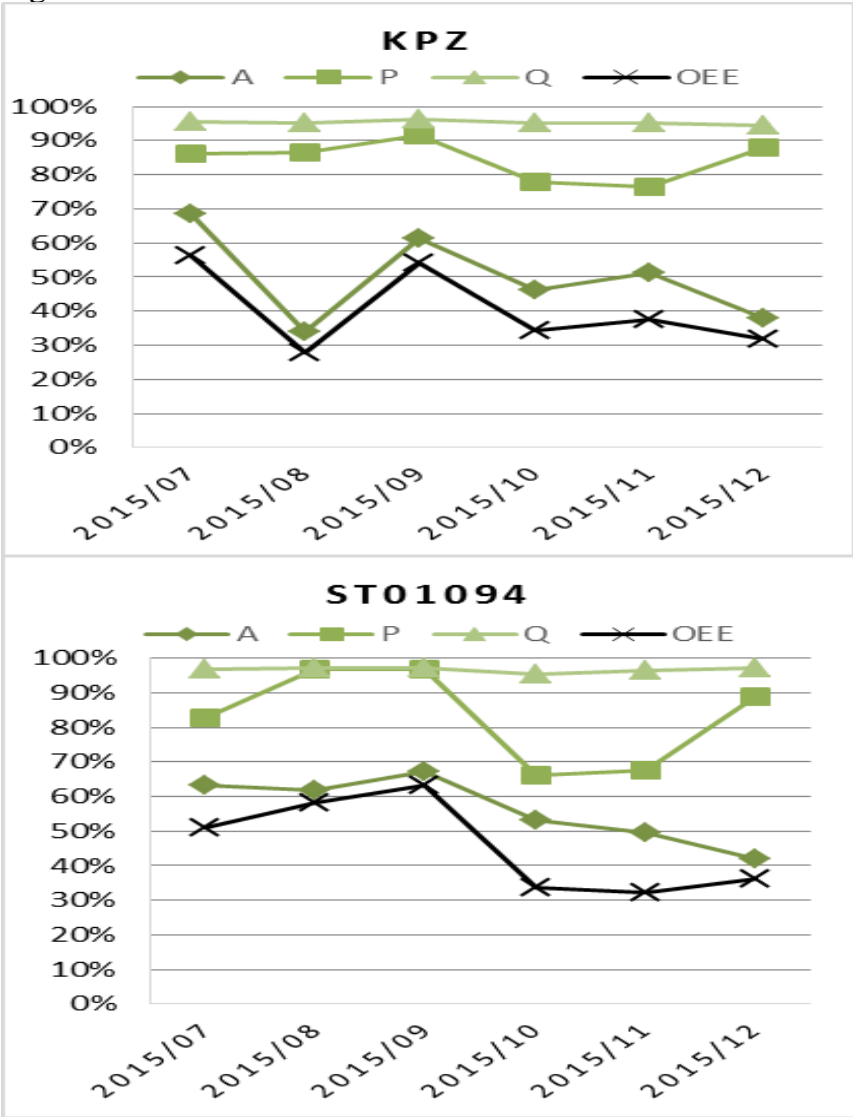

Figure 2. OEE measure distribution in time for all the casting machines (KZT) and for the one selected (STO1094)

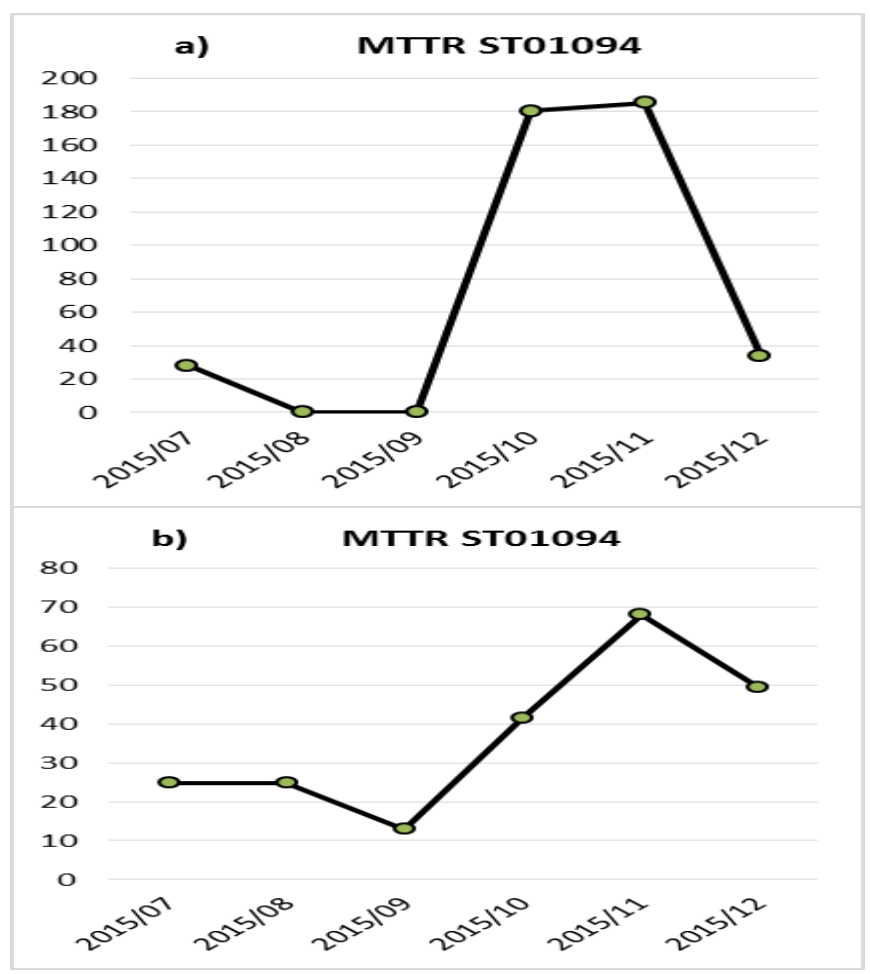

Figure 3. MTTR for a casting machine a) monthly, b) cumulative graph

According to the assumptions take, implementation of OEE should lead to identification of areas of operational improvement of activities for both production and maintenance staff. Analysis of Figure 2 highlights the very high value of Quality rate for all the casting machines, which is good news. In contrast, the value of Availability rate is disturbing. It is the main cause of low value OEE.

The first step of the research was analysis of losses (TABLE II), records in the computer system, and executive instructions for operators and interviews with operators. In order to effectively use the OEE, the data required for calculation must be clearly defined, and well structured (clearly assigned to the appropriate category of losses), to be credible, and so the staff recording the data need to understand what they do and have a real the opportunity to do this. As the result of the activities carried out it was found that the primary problem is the incorrect data entered into the system by operators, lack of performance standards for the maintenance work carried out on the machine by operators, improper organization of work and the lack of employee awareness (what is it for?) - The employees do not see the interdependences. Thus, the improvement must go towards the standardization of the operators work and building awareness and motivation to comply with the rules and standards developed.

In the next step the relationship between the "Availability rate" and values MTTR, MTBF and MTTF were sought for. These indicators were measured in a company for a long time and were input to the maintenance activities schedules 
and to evaluation of the effectiveness of these actions. The impact of MTTR indicator on "Availability rate" and thus on the value of the OEE is obvious. The calculation of this ratio in a cumulative way enables determination of the trend, but its precision is very limited. However, the analysis of the indicator has led to the conclusion that such large losses of availability are not the result of negligence of maintenance staff. The author did not manage to find the links with other indicators (e.g. MTBF, MTTF), which would allow accurate determination of trends and implementation of appropriate measures for the planning and scheduling maintenance work. Moreover, conclusion on a single machine made on the basis of the whole group has not produced the expected results (no correlation). Therefore, the calculated value of the OEE for all the casting machines can only be used as the internal benchmark.

Hence, the summary of the research from the perspective of the activities of maintenance shows that the OEE model developed does not provide clear and precise information to enable appropriate control of processes on specified machines, so monitoring of several indicators (MTTR, OEE, MTBF, MTTF) seems to be the right step, and in combination with the knowledge base SUR (base designed for the needs of enterprise to collect and analyze data on machine operation) enables the development of effective maintenance plans.

\section{CONCLUSION}

OEE is a "best practices" way to monitor and improve the effectiveness of processes (i.e. machines, manufacturing cells, assembly lines). The OEE tool evaluates equipment performance, which could provide a basis for further improvement. It maps out the "losses landscape"; speed loss, machine breakdown and minor stoppages, defect loss, and so on. All those details are integrated into the single tool. This article highlights three important issues related to the OEE measure. Firstly, the multiplicity of approaches for determining losses and corresponding models for calculating OEE (Chapter 2) was shown. Although this situation may cause some confusion, it reflects the potential of this measure in relation to the assessment of efficiency of production equipment of various businesses and industries. Secondly, OEE can be used not only to monitor losses. Its real value is providing information concerning opportunities for improvement. $\mathrm{OEE}$ is a useful guide for production processes managers striving for improving and building internal cooperation with other functional areas of the company, e.g. production, maintenance, logistics. Another, third aspect resulting from the case study presented is the issue of availability and reliability of the data necessary to calculate the OEE. According to Muchiri and Pintelon [26], the validity and usefulness of the OEE measure are highly dependent on the data collection and accuracy. Without reliable data, the different losses cannot be measured and identified. It is therefore important to invest time and money to improve data collection. For this reason some manufacturing companies have automated their collection of OEE-related data to guarantee the data accuracy.

It is also important to know that the OEE provides an excellent perspective of a comprehensive improvement achievement, but e.g. in the area of maintenance should be strengthened indicators such as MTBF, MTTF and MTTR.

\section{REFERENCES}

[1] A. Mazur and A.Stachowiak, "The framework of methodology for identification of organizational maturity with assessment of excellence level of logistics systems," in: Abrudan I (ed.), The Management between profit and social responsibility, Procedeengs of the $4^{\text {th }}$ Review of Management and Economic Engineering International Management Conference, 18-20 September 2014, Todesco Publishing House, Cluj-Napoca, Romania, pp. 415-423, ISSN $2247-8639$

[2] E. Więcek-Janka, R. Mierzwiak, J. Kijewska, “Competencies' Model in the Succession Process of Family Firms with the Use of Grey Clustering Analysis," The Journal of Grey System, vol. 28, no.2, pp. 121-131, 2016.

[3] A. Rudawska, N. Čuboňova, K. Pomarańska, D. Stanečková and A. Gola, "Technical and Organizational Improvements of Packaging Production Processes," Advances in Science and Technology. Research Journal, vol. 10, no.30, pp. 182-192, 2016. DOI: $10.12913 / 22998624 / 62513$.

[4] M. Jasiulewicz-Kaczmarek, "Practical aspects of the application of RCM to select optimal maintenance policy of the production line," in: T. Nowakowski et al (ed.), Safety and Reliability: Methodology and Applications, 2015 Taylor \& Francis Group, London, pp. 1187-1195 Proceedings of the European Safety and Reliability Conference, ESREL 2014.

[5] A. Misztal, M. Butlewski, N. Belu and L.M. Ionescu, "Creating involvement of production workers by reliable technical maintenance", in: Proceedings of 2014 International Conference on Production Research - regional conference Africa, Europe and the Middle East and 3rd International Conference on quality and innovation in engineering and management, D. Popescu (ed.), Cluj Napoca, Romania, pp. 331-336.

[6] J.D. Campbell and A.K.S. Jardine, "Maintenance Excellence: optimising equipment life-cycle decisions," Marshall Dekker, New York, 2001.

[7] S.Nakajima, "Introduction to TPM. Total Productive Maintenance," Productivity Press, Portland, Oregon, 1988.

[8] B. Dal, P. Tugwell and R. Greatbanks, "Overall equipment effectiveness as a measure of operational improvement," International Journal of Operations \& Production Management, vol. 20, no.12, pp. 1488-502, 2000. DOI: 10.1108/01443570010355750.

[9] K-Y. Jeong and D.T. Phillips, "Operational efficiency and effectiveness measurement," International Journal of Operations \& Production Management, vol. 21, no.11, pp. 1404-1416, 2001. DOI: 10.1108/EUM0000000006223.

[10] A.S. Badiger and R. Gandhinathan R, "A proposal: evaluation of OEE and impact of six big losses on equipment earning capacity," International Journal Process Management and Benchmarking, vol. 2, no3, pp. 356-376, 2008. DOI: 10.1504/EJIE.2008.017690.

[11] Shahin and N.G. Isfahani, Estimating overall equipment effectiveness for continuous production lines: With a case study in Esfahan Steel Company," International Journal of Services and Operations Management vol. 21, no.4, pp. 466-478, 2015. DOI: 10.1504/IJSOM.2015.070252.

[12] D. Yuniawan, T. Ito and E.B. Mohamad, "Overall equipment effectiveness estimation for priority improvement in the production line," International Journal of Internet Manufacturing and Services vol. 3, no.4, pp.279-299, 2014

[13] P.N. Raja, S.M. Kannan and V. Jeyabalan, "Overall line effectiveness - A performance evaluation index of a manufacturing system," 
International Journal of Productivity and Quality Management vol. 5, no.1, pp. 38-59, 2010. DOI: 10.1504/IJPQM.2010.029508.

[14] R.M. Nachiappan and N. Anantharaman, "Evaluation of overall line effectiveness (OLE) in a continuous product line manufacturing system," Journal of Manufacturing Technology Management, vol. 17, no.7, pp. 987-1008, 2006. DOI: 10.1108/17410380610688278.

[15] D. Scott and R. Pisa, "Can Overall Factory Effectiveness Prolong Moore's Law?," Solid State Technology, vol.41, no.3, pp.75 - 82, 1998.

[16] M. Braglia, M. Frosolini and F. Zammori, "Overall equipment effectiveness of a manufacturing line (OEEML): An integrated approach to assess systems performance," Journal of Manufacturing Technology Management vol. 20, no.1, pp. 8-29, 2008. DOI: 10.1108/17410380910925389.

[17] K. M. N. Muthiah, S.H. Huang and S. Mahadevan, "Automating factory performance diagnostics using overall throughput effectiveness (OTE) metric," International Journal of Advanced Manufacturing Technology , vol.36, pp. 811-824, 2008. DOI: 10.1007/s00170-006-0891-x.

[18] R. Domingo and S. Aguado, "Overall Environmental Equipment Effectiveness as a Metric of a Lean and Green Manufacturing System”, Sustainability, vol.7, pp. 9031-9047, 2015. DOI:10.3390/su7079031.

[19] K.M.N., Muthiah and S.H. Huang, "Overall throughput effectiveness (OTE) metric for factory-level performance monitoring and bottleneck detection," International Journal of Production Research, vol. 45, no.20, pp. 4753-4769, 2007. DOI:10.1080/00207540600786731

[20] R. Oechser, M. Pfeffer, L. Pftzner, H. Binder, E. Muller and T. Vonderstrass, From Overall Equipment Effectiveness to Overall Fab
Effectiveness (OFE), Material Science in Semiconductor Processing 5(4-5), 2003, pp. 333-339, DOI:10.1016/S1369-8001(03)00011-8.

[21] P.H. Tsarouhas, "Evaluation of Overall Equipment Effectiveness in the Beverage Industry: A Case Study," International Journal of Production Research vol. 51, no.2, pp. 515-523, 2013. DOI: 10.1080/00207543.2011.653014.

[22] F. Anvari, R. Edwards and A. Starr, "Evaluation of overall equipment effectiveness based on market," Journal of Quality in Maintenance Engineering, vol. 16, no.3, pp. 256-270, 2010. DOI $10.1108 / 13552511011072907$.

[23] F. Anvari and R. Edwards, "Performance measurement based on a total quality approach," International Journal of Productivity and Performance Management, vol. 60, no.5, pp. 512-528, 2011. DOI: 10.1108/17410401111140419.

[24] P. Kumar, R. Shetty and L.L.R. Rodrigues, "Overall Equipment Efficiency and Productivity of a News Paper Printing Machine of a Daily News Paper Company - A Case Study," International Journal of Engineering Practical Research, vol. 3, no1, pp. 20-27, 2014. DOI: 10.14355/ijepr.2014.0301.04.

[25] R. Wudhikarn, R., "Implementation of the overall equipment cost loss (OECL) methodology for comparison with overall equipment effectiveness (OEE)," Journal of Quality in Maintenance Engineering, vol.22,no.1, pp. 81 - 93, 2016. DOI: 10.1108/JQME-12-2011-0001

[26] Muchiri, P., Pintelon, L., 2008. Performance measurement using overall equipment effectiveness (OEE): Literature review and practical application discussion, International Journal of Production Research, vol.46, no.13, pp. 1-45. 